\title{
Retracted: Research on Crude Oil Trade Procurement Model Based on DEA-Malmquist Algorithm
}

\author{
Scientific Programming
}

Received 7 April 2022; Accepted 7 April 2022; Published 10 May 2022

Copyright @ 2022 Scientific Programming. This is an open access article distributed under the Creative Commons Attribution License, which permits unrestricted use, distribution, and reproduction in any medium, provided the original work is properly cited.

Scientific Programming has retracted the article titled " $\mathrm{Re}$ search on Crude Oil Trade Procurement Model Based on DEA-Malmquist Algorithm" [1], due to concerns with the authenticity of the data. It was found that previous versions of this submission contained a figure unrelated to the topic of the paper and this graph was subsequently identified within several other submissions, all with accompanying text claiming to have generated the graph. A number of these submissions were rejected from the journal; however, 6 were published and have now been retracted from Security and Communication Networks and Scientific Programming [2-6].

The authors responded to explain that an author from one of the identified submissions had provided copy editing for their manuscript and introduced the graph and accompanying text in error.

The authors were unable to provide copies of correspondence to support their claim or the raw data from their study. The authors' explanation did not satisfy the concerns of the editorial board, and the article is therefore being retracted due to concerns with the reliability of the data.

The authors do not agree to the retraction.

\section{References}

[1] L. Yan, "Research on Crude Oil Trade Procurement Model Based on DEA-Malmquist Algorithm," Scientific Programming, vol. 2021, Article ID 6360439, 10 pages, 2021.

[2] L. Fan, M. Xia, P. Huang, and J. Hu, "Research on Educational Information Platform Based on Cloud Computing," Security and Communication Networks, vol. 2021, Article ID 3109473, 11 pages, 2021.

[3] L. Huo, "Intelligent Recognition Method of Vehicle Path with Time Window Based on Genetic Algorithm," Security and Communication Networks, vol. 2021, Article ID 3614291, 11 pages, 2021.
[4] L. Keshun, Z. Xijun, and Z. Xing, "Research on Analysis and Classification of Vulnerability of Electromagnetic Pulse with a STM32 Single-Chip Microcomputer," Scientific Programming, vol. 2021, Article ID 6836158, 10 pages, 2021.

[5] L. Zhuang, Y. Qi, and F. Zhang, "Braking Control System of Oilfield Minor Repair Machine Based on Wireless Sensor Network," Security and Communication Networks, vol. 2021, Article ID 6966041, 14 pages, 2021.

[6] G. Yin, R. Qi, J. Zhao, X. Zhao, and J. Xu, "Optimization Method of Sports Service Network Node Layout Based on Network Communication," Security and Communication Networks, vol. 2021, Article ID 3013135, 8 pages, 2021. 


\title{
Research on Crude Oil Trade Procurement Model Based on DEA-Malmquist Algorithm
}

\author{
Liu Yan (1) \\ School of Economics and Management, Shihezi University, Shihezi 832000, China \\ Correspondence should be addressed to Liu Yan; liuyan@stu.zuel.edu.cn
}

Received 7 October 2021; Accepted 8 December 2021; Published 27 December 2021

Academic Editor: Jamil Hussain

Copyright @ 2021 Liu Yan. This is an open access article distributed under the Creative Commons Attribution License, which permits unrestricted use, distribution, and reproduction in any medium, provided the original work is properly cited.

\begin{abstract}
To retain valuable information to the maximum extent and enhance the ability to mine the crude oil trade purchase price demand, this paper proposes a crude oil trade purchase model based on the DEA-Malmquist algorithm. The intranet of the management and control platform shall share the same database, and the intranet shall only allow managers to access and manage the system and only allow all registered users to access and realize data exchange between the intranet and the intranet through twodimensional code scanning; moreover, due to the resource sharing between the intranet and the intranet for crude oil trade procurement, suppliers and other registered users can immediately grasp the procurement trends of enterprises. Under the DEAMalmquist algorithm, the uncertainty of procurement management is analyzed by fuzzy theory, and the refined procurement decision model with fuzzy parameters is established. The optimal order time and purchase quantity are determined through the symbol distance and the method of the center of gravity. Experimental results show that the method can effectively retain valuable information in the initial sequence and has better practical application value of material procurement demand intelligent mining. The proposed model obtained the highest accuracy of $98.62 \%$.
\end{abstract}

\section{Introduction}

Crude oil is one of the most widely used energy sources and the most important commodity in the global economy [1]. The current difficulty lies in the weak interaction between the crude oil trade information system at the front end of the design and the material demand calculation ability. The high-quality equipment, universal design, and standard materials were not applied in the early stage of the design, and the procurement standards were in contradiction between supply and demand at both ends. It has not been effectively improved, and the standardization of design sources is encouraged, and the resistance of suppliers is relatively high. At the same time, procurement standardization of intelligent applications has been lacking. With the rapid economic development, the scale of crude oil trade procurement has become larger and larger, and the types and quantities of procurement have increased year by year [2]. Reasonable use of crude oil trade procurement mode is of great significance to the benign development of enterprises or countries.
Reference [3] presents the time-varying impact of crude oil shocks on trade balance based on the TVP-VAR model and studies the impact of crude oil supply and demand shocks on the Sino-Russian current account balance from the first quarter of 1993 to the third quarter of 2018 by using the stochastic time-varying parameter vector autoregressive (TVP-VAR) model. Focus was on two countries with different characteristics of crude oil trade: Russia, as a crude oil exporter, and China, as a crude oil importer. Identifying their sources is important in mitigating the impact of crude oil price shocks on the trade balance. Reference [4] presents the remote connection of global crude oil networks: a comparison of direct trade and actual flows. To illustrate the gap between crude oil trade and consumption, the internal strength of the remote connection of global crude oil is calculated, the topological differences are compared, and the energy risks between direct crude oil trade networks and specific crude oil transport networks are examined. There is a significant difference between a direct trade network and a concrete transfer network. The direct trade network has less relationship but higher internal strength, while the crude oil 
transport network has lower internal strength. In terms of regional composition, the countries with rich crude oil resources and a high degree of industrialization occupy the core circle of crude oil direct trade network, while the countries with a high degree of industrialization occupy the core position of the crude oil transfer network. It is found that the topology of a data communication network plays an important role in its security robustness against attack. In such mobile computing, the computing robustness against an intentional attack that aims to bring down network nodes may vary by changing the topology. This bringing down is a kind of destruction and interruption threat that attacks the availability of the network (i.e., attack on network resources and links).

Although the research has made some progress to retain valuable information and enhance the ability to mine the demand of crude oil trade purchase price, this paper studies the crude oil trade purchase mode based on the DEAMalmquist algorithm. As for the crude oil trade, purchase mode faces a series of changes, such as the change from a cost center to a profit center and a strategic driving force. Adoption of purchase is an indispensable economic behavior in modern economic activities. In a narrow sense, adoption of purchase refers to the transaction of enterprises or the state under certain conditions to purchase the goods and services necessary for their production and operation from the supply market. It is found that the designed crude oil trade procurement model has good mining ability, which lays a solid foundation for intelligent mining of crude oil trade procurement needs.

Key contributions of the study are enumerated as follows:

(1) An accurate crude oil trade purchase model is proposed by adopting DEA-Malmquist algorithm

(2) A refined procurement decision model is proposed using DEA-Malmquist algorithm and fuzzy logic

(3) An efficient way of handling the uncertainty in procurement model is achieved by analyzing and using fuzzy theory

This paper is divided into six sections. Section 2 briefly introduces the crude oil trade procurement model framework, while Section 3 introduces DEA preliminary. Our proposal can be described in Section 4 in detail. Section 5 describes the experimental results. Section 6 concludes this paper with contributions, limitations, and future works.

\section{Crude Oil Trade Procurement Model Framework}

Data collection is a key operation. Because of the existing data collection schemes' privacy-preserving problem, we utilize a secure and verifiable continuous data collection (SVCDC) algorithm to collect data for the education information platform. Considering the temporal correlation of sensory data, SVCDC algorithm reconstructs multiple sensory data in one period, which can effectively decrease data traffic, and then, by encrypting the reconstructed data, SVCDC algorithm ensures the privacy of the sensory data.

2.1. Overall Framework of Crude Oil Trade Procurement Platform. Figure 1 shows the overall framework of the platform for the crude oil trade procurement mode. The horizontal dotted line separates the internal and external network, the upper part of the dotted line is the external network of the enterprise, any user can access the website, and the lower part of the dotted line is the intranet of the crude oil trade procurement enterprise. Only those with authority can access the network, and the network contains two independent application systems.

\subsubsection{Intranet Procurement Management Information} System. Corporate intranet supervision is mainly to supervise whether the procurement process of the procurement department is reasonable. Authorized management personnel can access the intranet system through browsers. The intranet system includes supplier information, product information, review expert information, organization management, user management, procurement announcements release, external network data maintenance, procurement project establishment, tracking, archiving, and other functions. In this intranet, there is an item that the top management can only view: rich charts and statements generated automatically to provide effective data support for top management decisions.

2.1.2. Provider Management and External Network Announcement Platform. The main task of the extranet system is to synchronize the procurement information announcements made by the intranet system and provide the suppliers with the procurement information they need in real time [5], so that the suppliers can prepare the materials. In the extranet system, suppliers can register enterprise information, maintain and add their own materials, and make the enterprise procurement department build a complete set of product resource information databases.

The product resource information database can provide useful information for the intranet system at the same time. The supplier data, product data, and bulletin information can be found in the database.

\subsection{System Logic Framework}

2.2.1. Logical Structure of Intranet System for Crude Oil Trade Procurement. Intranet logic framework for crude oil trade procurement is shown in Figure 2.

As shown in Figure 2, the intranet system for crude oil trade procurement is divided into three major parts: portal, business, and data. The portal layer is mainly responsible for accessing registered users to the system. All administrators with authority may access the internal enterprise network through any browser, and, before entering the intranet, the Web Server shall process the access request, encapsulate the request, and send the request to the server. 


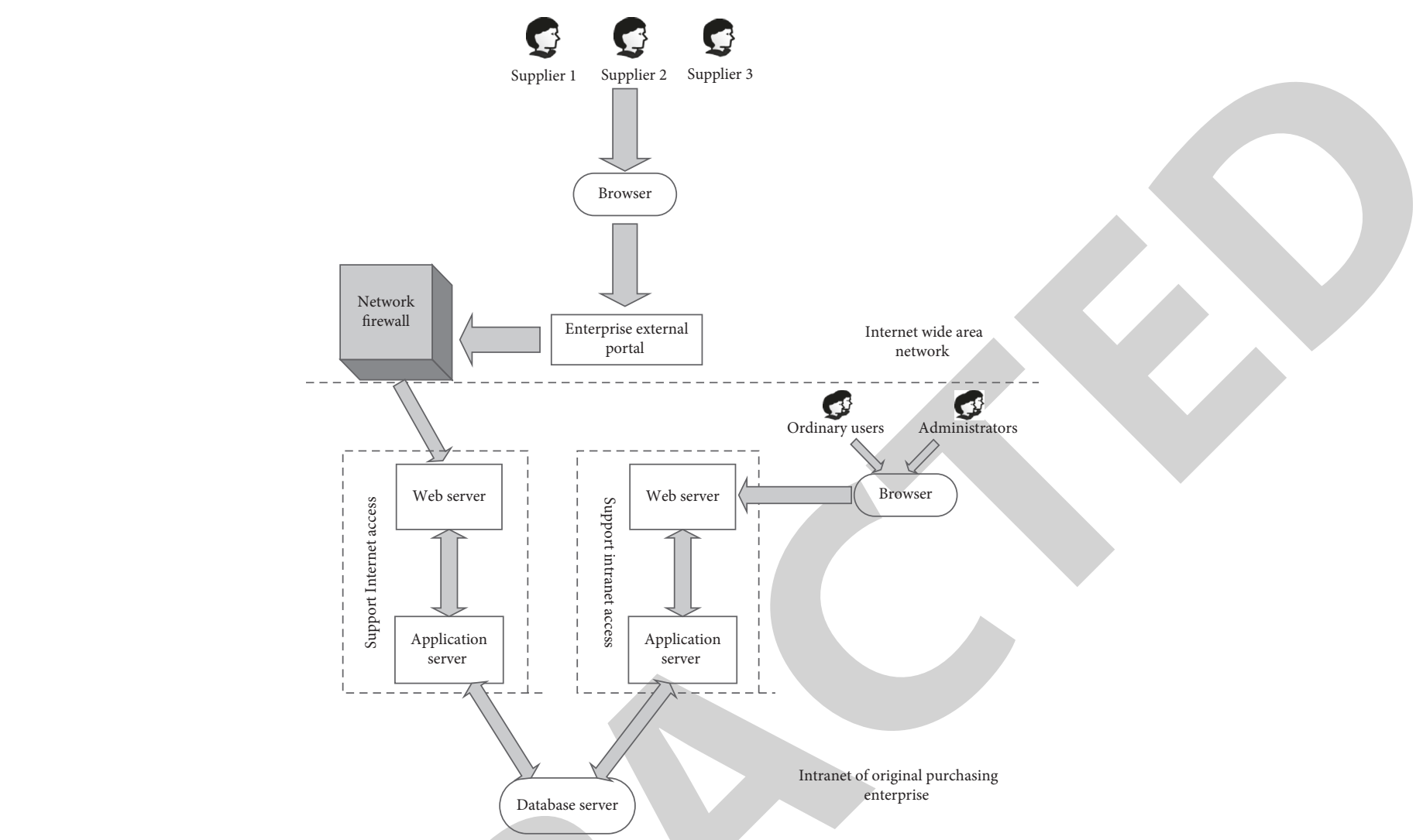

FIgURE 1: Overall framework of the crude oil trade procurement model.

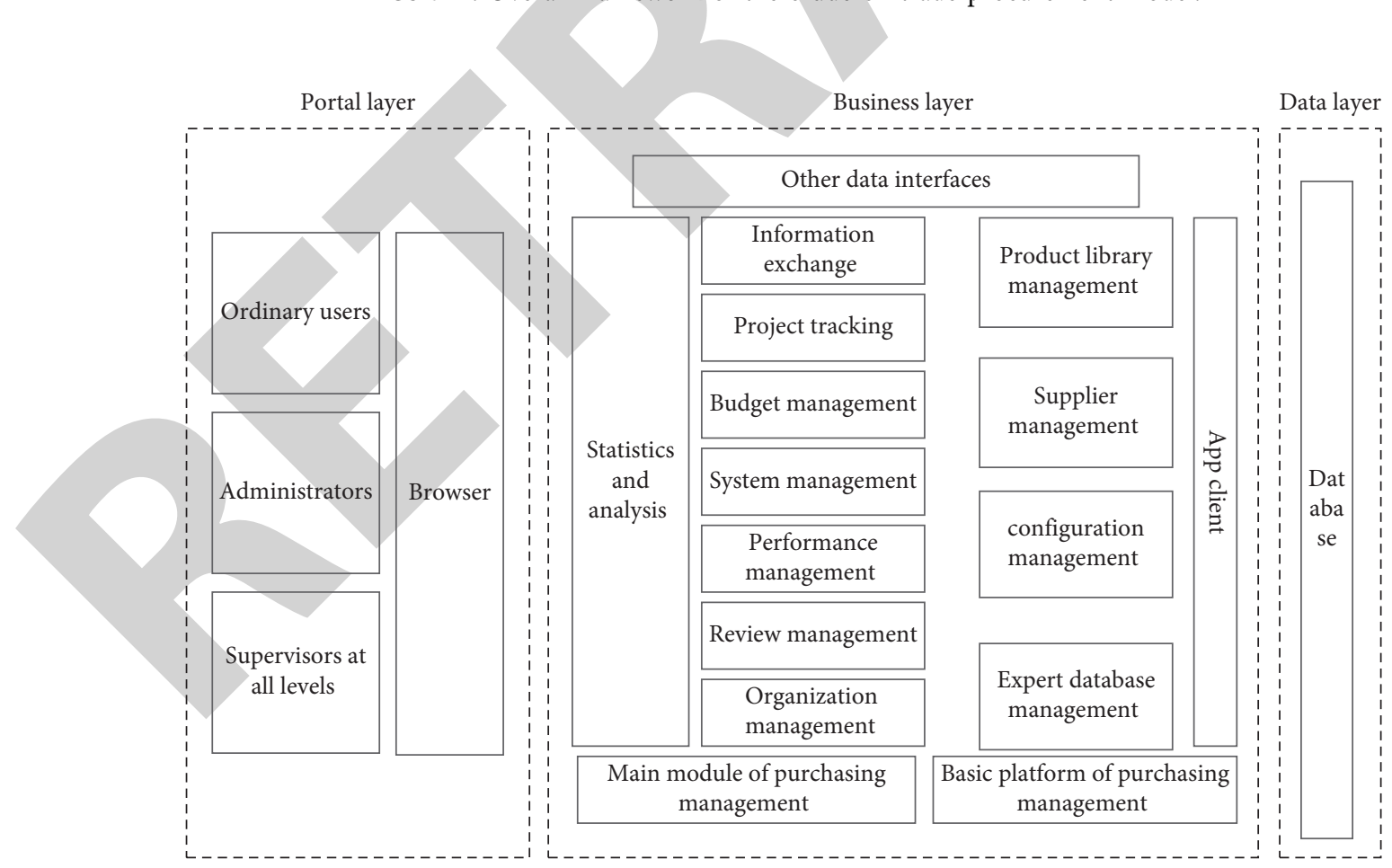

Figure 2: Intranet logic framework for crude oil trade procurement.

The main task of the business layer is to handle the demands from the Web Server [6] and support the whole business layer by using the APP terminal. The business layer is also called the function layer, which is the main measure to realize the functions of the intranet system, including the basic part of procurement management, the main part of procurement management, and the interface function with other systems. The data layer refers to the 
data persistence of the business layer through the Sybase ASE database [7]. The proposed DEA-Malmquist algorithm is used at the data layer.

\subsubsection{Logical Structure of the Outer Network System for} Crude Oil Trade Procurement. Logical framework of outer network for crude oil trade procurement is shown in Figure 3.

The extranet system is also divided into three parts: portal layer, business layer, and data layer. Among them, the main function of the portal layer is still the user access, and the user accesses the extranet system by using the browser under the condition of having a network, processes the access request through the Web Server, and sends the request to the server after encapsulating the request. The main tasks and processing functions of the business layer are the same as those of the intranet, but the functions of the extranet are the homepage of the website, news, announcement information, registration of suppliers, maintenance of suppliers, the introduction of the institution, and so forth. The data layer also uses the Sybase ASE database to keep the data persistent at the business layer. Ensure that the intranet and extranet data layers are the same, access the same database, and then realize intranet and extranet data sharing.

In the last three years, many methods were proposed to handle the problem of the intelligent recognition method of crude oil; here we introduced three outstanding methods as GCoP [8] (global complexity of procurement), ReOT [9] (residual of trade), and KS++ [10] (conventional network based), which can be used to solve the related works taking different kinds of network structures. GNB is a network that builds global connections between different risk nodes and their complexity. RNB uses a specific loss structure to keep the similarity of real and predicted crafts design. $\mathrm{KS}++$ is the basic model that needs more computation consumption to obtain the desiring performances. However, these methods have their disadvantages, respectively. GNB is too slow, RNB is so complicated, and $\mathrm{KS}++$ also needs more spaces. Compared with these methods, our proposal can work well effectively for path identification by using the evolving algorithm that does not utilize the network structure and is not time-consuming. The proposed DEA-Malmquist algorithm is used at the data layer.

\section{DEA-Malmquist Algorithm for Crude Oil Trade}

The Data Envelopment Analysis (DEA) approach constructs the optimal production frontier primarily from the extremes of all DMUs [11] and compares other DMU values to derive its relative effectiveness. At present, the basic models of DEA mainly include CCR, BCC, superefficiency, and equilibrium index model.

3.1. DEA-BCC Static Model. BCC is a DEA model which is based on the premise that the return to scale can be changed [12]. This model improves the defect of assuming the return

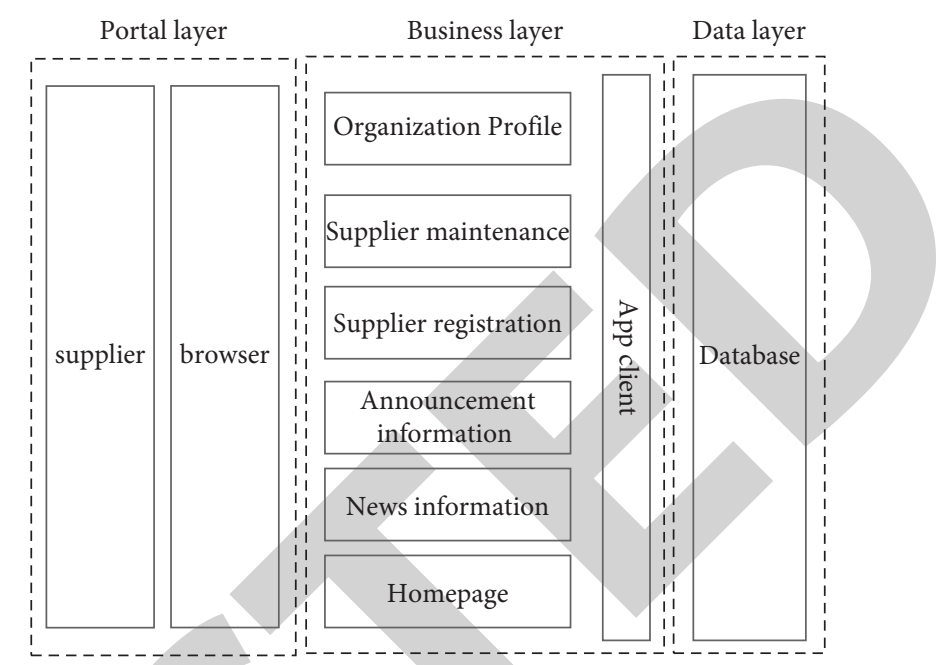

FIGURE 3: Logical framework of outer network for crude oil trade procurement.

to scale in the original CCR model and decomposes the technical efficiency into scale efficiency and pure technical efficiency. Scale efficiency is used to measure whether the inputs and outputs of each DMU are in the state of maximizing scale income, reflecting the level of strategic planning of enterprises. Under this model, total efficiency $=$ technical level $\times$ scale efficiency $\times$ pure technical efficiency. The model is as follows:

$$
F=\left\{\begin{array}{l}
\sum_{j=1}^{n} X_{j} \mu_{j}+g^{-}, \\
\sum_{j=1}^{n} Y_{j} \mu_{j}-g^{+}, \\
\mu_{j} \geq 0, g^{-}, g^{+} \geq 0 .
\end{array}\right.
$$

In the formula, $j=1,2, \cdots, n$ represents decision unit, and $X_{j}$ and $Y_{j}$ are input and output vectors, respectively. If $\mu_{j}=1$ and $g^{-}, g^{+}=0$, then DMU and DEA are valid. If $\mu_{j}=$ 1 and $g^{-}, g^{+} \neq 0$, then DMU weak DEA is good. If $\mu_{j}<1$, then DMU and DEA are invalid.

3.2. DEA-Malmquist Dynamic Exponential Model. The Malmquist productivity index was first proposed by Malmquist in the 1950s [13], which was combined with the DEA method to reflect the trend of production efficiency of the main body. The formula is as follows:

$$
D=\sqrt{\frac{H_{a}\left(x_{1}, y_{1}\right)}{H_{a+1}\left(x_{a+1}, y_{a+1}\right)}}=S_{c} \times P_{v} \times T_{e} .
$$

In the above formula, $D$ represents total factor productivity [14], $S_{c}$ represents scale efficiency index, $P_{v}$ represents pure technical efficiency index, and $T_{e}$ represents technological change index. If $D$ value is greater than 1 , it indicates that total factor productivity is in a positive growth trend, while overall performance is rising; otherwise, it is declining. If $S_{c}$ is greater than 1 , it means that the current 
production scale and R\&D investment level are close to the optimal ratio; otherwise, it is far from the optimal ratio. If $S_{c}$ is greater than 1, it means that technological level plays a promoting role on innovation performance; otherwise, it hinders innovation performance. $T_{e}$ is greater than 1 , indicating that $\mathrm{R} \& \mathrm{D}$ technology is improving; otherwise, it is declining [15].

Assume that the maximum delay that the real-time material procurement service can accommodate is $R_{o}$ and the data rate is $W_{b}$. Let the data generated by the material procurement service source be assembled to the length of the data packet $P_{d}$. To ensure the continuity of real-time material procurement business, the number of data packets that must be transmitted within $R_{o}$ time is

$$
B_{c}=\frac{R_{o}}{P_{d}} \times W_{b} \times D .
$$

The DEA-Malmquist algorithm polls the nodes through the point coordinator and centrally controls the access of the system channels. The DEA-Malmquist algorithm is called DEA for short. Under the DEA-Malmquist algorithm, the transmission channel time of crude oil trade procurement data is divided into many superframes with the length of $T_{\mathrm{SF}}$, and the superframe at moment $R_{o}$ is

$$
I_{t}=\frac{R_{o}}{T_{\mathrm{SF}}} \times B_{c} .
$$

After the above process, it can be concluded that, under the DEA-Malmquist algorithm, the real-time crude oil trade procurement business requires to be completed within $I$ hyperframes and $B$ transmission packets, so $(I, B)$ is taken as the service standard of the real-time material procurement business.

Therefore, the expression of the service standard for realtime material procurement is as follows:

$$
\left\{\begin{array}{l}
I=\frac{R_{o}}{T_{\mathrm{SF}}} \\
B=\frac{I_{t}}{P_{d}} \times T_{\mathrm{SF}} \times W_{b}
\end{array}\right.
$$

In the above formula, $I$ represents the service interval and $B$ represents the number of service packets. Four input indicators and four output indicators are selected in the crude oil trade procurement mode, as shown in Table 1.

\section{Optimal Decision Model for Crude Oil Trade Procurement Based on DEA- Malmquist Algorithm}

Let $X$ represent the domain and let $\widetilde{A}$ be a subset of $X$. For $\forall x \in X$ and the function $\mu_{\tilde{A}}(x): X \longrightarrow[0,1], \mu_{\tilde{A}}(x) \in$ $[0,1]$, where $\mu_{\tilde{A}}(x)$ reflects the degree to which $x$ belongs to
$\widetilde{A}, \widetilde{A}$ is called the fuzzy set [16], and $\mu_{\tilde{A}}(x)$ is called the membership function of $\widetilde{A}$.

The membership function of triangular fuzzy function $\widetilde{A}=(a, b, c)$ is

$$
\mu_{A}(x)= \begin{cases}\frac{x-a}{b-a}, & a \leq x \leq b, \\ 0, & x \leq a, x>c, \\ \frac{c-x}{c-b}, & b<x \leq c .\end{cases}
$$

Under the DEA-Malmquist algorithm, changes in the two following aspects need to be taken into account in the process of crude oil trade procurement:

(1) Due to the change of design, there exists the phenomenon of material waste in the actual work process, and, at the same time, the natural environment factors will also affect the change of material demand in crude oil trade procurement

(2) When the contractor procures materials for the crude oil trade, changes in factors such as travel expenses and handling charges of the procurement personnel for the crude oil trade may also result in different order fees for construction materials purchased for each crude oil trade

Combined with the above analysis, the model is constructed through the existing uncertainty factors. The following assumptions are required for the model:

(1) Crude oil trade procurement of single material

(2) The missing materials being able to be replenished in an instant

(3) Using the $t$ - loop strategy

Set $\widetilde{R}$ to represent the demand of materials in time period $t$, where

$$
\widetilde{R}=\left[R_{0}, R_{1}, R_{2}\right] .
$$

In the above formula, $R_{0}$ represents the minimum quantity of material required; $R_{1}$ represents the average demand for materials; $R_{2}$ represents the maximum demand for the material.

$\widetilde{A}$ represents the cost required for each purchase of crude oil trade, where

$$
\widetilde{A}=\left[A_{0}, A_{1}, A_{2}\right] .
$$

In the formula, $A_{0}$ represents the minimum subscription fee; $A_{1}$ stands for normal subscription fee; $A_{2}$ stands for maximum subscription fee.

Assuming that the fuzzy number of order cost of crude oil trade procurement is [17] $\widetilde{A}=\left[A_{0}, A_{1}, A_{2}\right]$, the corresponding membership function is [18] 
TABLE 1: Input and output indicators for the crude oil trade procurement model.

\begin{tabular}{|c|c|c|}
\hline Index & Name & Reflect the situation \\
\hline \multirow{4}{*}{ Input index } & Proportion of R\&D personnel & Reflect the structure of R\&D personnel \\
\hline & $\begin{array}{l}\text { The proportion of masters and } \\
\text { above }\end{array}$ & Reflect the structure of highly educated personnel and the overall quality of employees \\
\hline & R\&D expenditure & It reflects the scale of $R \& D$ investment \\
\hline & $\mathrm{R} \& \mathrm{D}$ investment intensity & It reflects the $R \& D$ input level of the enterprise after removing the influence of scale \\
\hline \multirow{4}{*}{$\begin{array}{l}\text { Output } \\
\text { indicators }\end{array}$} & $\begin{array}{l}\text { Growth rate of operating } \\
\text { revenue }\end{array}$ & It reflects the growth rate of business income brought by enterprise $\mathrm{R} \& \mathrm{D}$ activities \\
\hline & Net profit & Reflect the profit brought by the enterprise's $\mathrm{R} \& \mathrm{D}$ activities \\
\hline & Proportion of technical assets & $\begin{array}{c}\text { Reflect the proportion of intangible assets in the total assets to measure the overall } \\
\text { quality of enterprise assets }\end{array}$ \\
\hline & Capital accumulation rate & Reflect the change of owner's equity caused by enterprise's R\&D activities \\
\hline
\end{tabular}

$$
\mu_{\tilde{A}}(x)(A)= \begin{cases}\frac{A-A_{0}}{A_{1}-A_{0}}, & A_{0}<A \leq A_{1}, \\ 0, & A \leq A_{0}, x>A_{2}, \\ \frac{A_{2}-A}{A_{2}-A_{1}}, & A_{1}<A \leq A_{2} .\end{cases}
$$

Solve subscription fee ambiguity based on sign distance method:

$$
d(\widetilde{A}, 0)=\frac{1}{2} \int_{0}^{1}\left[A_{L}(\alpha)+A_{R}(\alpha)\right] \mathrm{d} \alpha .
$$

Set $R_{1}$ to represent the normal demand of materials required to calculate through budget and system construction schedule without any objective factors; $R_{0}$ represents the minimum demand for material demand reduced by objective environment; $R_{2}$ represents the maximum amount of demand that the objective environment causes to increase the demand. As the increase or decrease in demand will lead to the increase in the purchase cost of crude oil trade, the following analysis will be conducted for two different situations.

When the actual demand rate $R<R_{1}$, the storage cost of materials will increase within the crude oil trade procurement cycle $T$. The calculation formula of the average storage volume $Q_{1}(T)$ that increased in cycle $T$ is [19]

$$
Q_{1}(T)=\frac{1}{T} \int_{0}^{T}\left(R_{1} T-R T\right) \mathrm{d} t .
$$

The average storage cost $f_{0}(R)$ in cycle $T$ is

$$
f_{0}(R)=\left\{\begin{array}{l}
k Q_{1}(T,) \\
\frac{k}{T} \int_{0}^{T}\left(R_{1} T-R T\right) \mathrm{d} t \\
\frac{k T}{2}\left(R_{1}-R\right) .
\end{array}\right.
$$

When demand $R$ increases, the purchase cost of crude oil trade will also increase.
Based on the above analysis, the decision-making model for crude oil trade procurement shall be refined to determine the best order date and the volume of crude oil trade procurement:

$$
\left\{\begin{array}{l}
Q^{*}=\frac{A_{1}}{T}+p R_{1}, \\
T^{*}=R_{1} T .
\end{array}\right.
$$

In this paper, we utilize the entropy loss function to build the model for our research problems. It can be defined as follows: $\operatorname{loss}(x, y)=\sum_{i=1}^{n}-p_{i} \log \left(1-p_{i}\right)$.

We have that $x$ and $y$ are represented as the real arts and crafts' score and difficulty and $y$ means the predicted score and difficulty of our proposal. $p_{i}$ means the probability of them when they are similar. The bigger the value of the loss was, the worse our proposal performed; and our proposal is used to train a model that fits the real and predicted arts and crafts so that the machine can assist the arts and crafts designed.

Compared with the three methods, our proposal can deal with the problems easily and we also need a smaller computation space to build our model. However, our model may obtain a relatively lower accuracy than others sometimes, which may make the prediction unstable.

\section{Experimental Results and Analysis}

5.1. Data Processing and Normalization. The tender procurement price of crude oil of a certain material branch from 2016 to 2020 is selected as the research object, and it is found after detailed analysis that the microbial degradation of crude oil is the key procurement material. Because the cumulative data of crude oil purchased in small quantity cannot meet the mining demand, the experiment only selects five models of the microbial degradation of crude oil to carry out the relevant experiments on the trade procurement mode of crude oil, which are marked with Type 1, Type 2, Type 3, Type 4, and Type 5, respectively. From 2016 to 2020, a total of 3,800 sets of crude oil trade procurement data were divided into 100 sets of data as test sets, and the rest were all training sets. 
Due to the difference of crude oil purchase volume of different models to different degrees, the normalized processing method is adopted to accelerate the processing of data by

$$
x=\frac{x-x_{\min }}{x_{\max }-x_{\min }} .
$$

In the above formula, $x_{\min }$ and $x_{\max }$ represent the minimum and maximum values of the initial sequence, respectively. Considering that material purchasing personnel will randomly extract material purchasing information from observation samples, it is necessary to solve it. The solving process is shown in Figure 4.

5.2. Experiment Results and Analyses. The above process allows the random extraction of material procurement information, which is finally shared using the following formula:

$$
y_{i}=\frac{\sum_{a=1}^{t} u_{a}}{\left(\lambda_{i} n\right)}
$$

In the above formula, $\lambda_{i} n$ represents the shared and unshared information of manufacturer $i$, and $u_{a}$ represents the level of information sharing. Wavelet classification and single-branch reconstruction were carried out on the initial sequence, and the experimental results are shown in Figure 5.

As can be seen from Figure 5, the decomposition and reconstruction of the high-frequency sequence of crude oil trade procurement mode can capture the disturbance in the initial sequence and not only effectively reduce the number of parameters and improve the convergence efficiency but also retain the sudden or hidden valuable information in the initial sequence of crude oil trade procurement mode.

For more details, we use the confusion matrix, accuracy, precision, and F1-score to evaluate the model performance. $T P$ represents the number of instances that belong to the positive class and are classified into positive classes. TN represents the number of instances that belong to the negative class and are classified into negative classes. FP represents the number of instances that belong to the negative class and are classified into positive classes. FN represents the number of instances that belong to the positive class and are classified into negative classes.

$$
\begin{aligned}
\text { accuracy } & =\frac{\mathrm{TP}+\mathrm{TN}}{\mathrm{TP}+\mathrm{TN}+\mathrm{FP}+\mathrm{FN}}, \\
\mathrm{F} 1-\text { score } & =\frac{2 * \text { precise } * \text { recall }}{\text { precise }+ \text { recall }}, \\
\text { Precision } & =\frac{\mathrm{TP}}{\mathrm{TP}+\mathrm{FP}}, \\
\text { recall } & =\frac{\mathrm{TP}}{\mathrm{TP}+\mathrm{FN}} .
\end{aligned}
$$

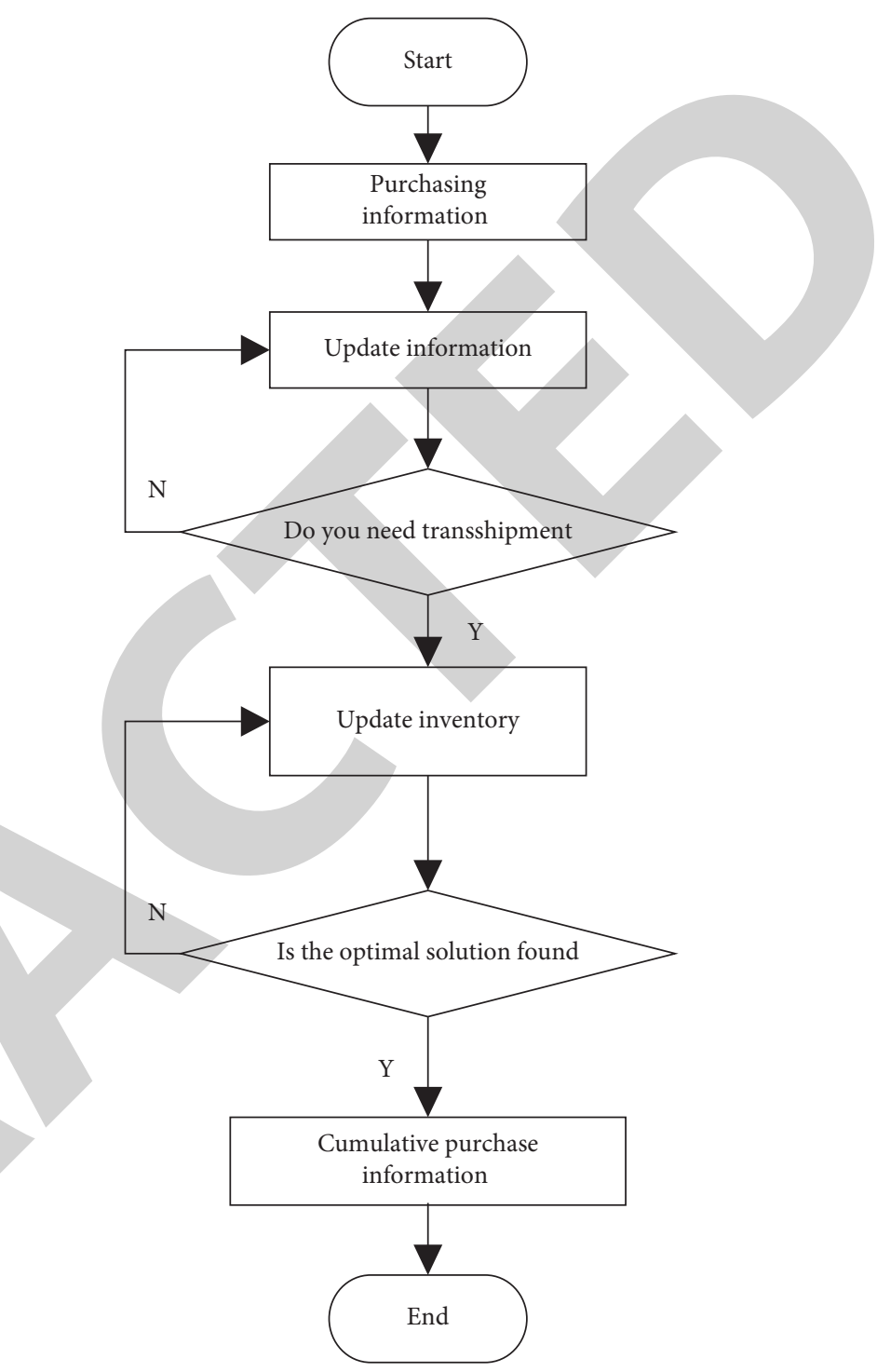

FIGURE 4: Flow of random material procurement information.

In order to verify the effectiveness of the method, we conducted simulation experiments on the basis of existing data. By comparing the success rates of different models in oil transactions in different countries and regions, we analyzed the accuracy of oil identification and the success of transaction recommendations by different models. Rates R1, $\mathrm{R} 2, \mathrm{R} 3$, and R4 represent different regions all over the world. Figure 6 shows the results of the rate of oil trade on different regions. From it, we can see that our proposal is better than others on R2, which indicated that our recommendation could perform better than the other three methods as we have enough trading experience on this region. ReOT also performs well in this region; however, GCoP performs well in R4. In addition, we also compared our proposal with four other types of neural networks; the results shown in Table 2 show that our proposal also perform better than them. It indicated that oil data are not suitable for these models as they lack inner connections and sufficient structure information. 


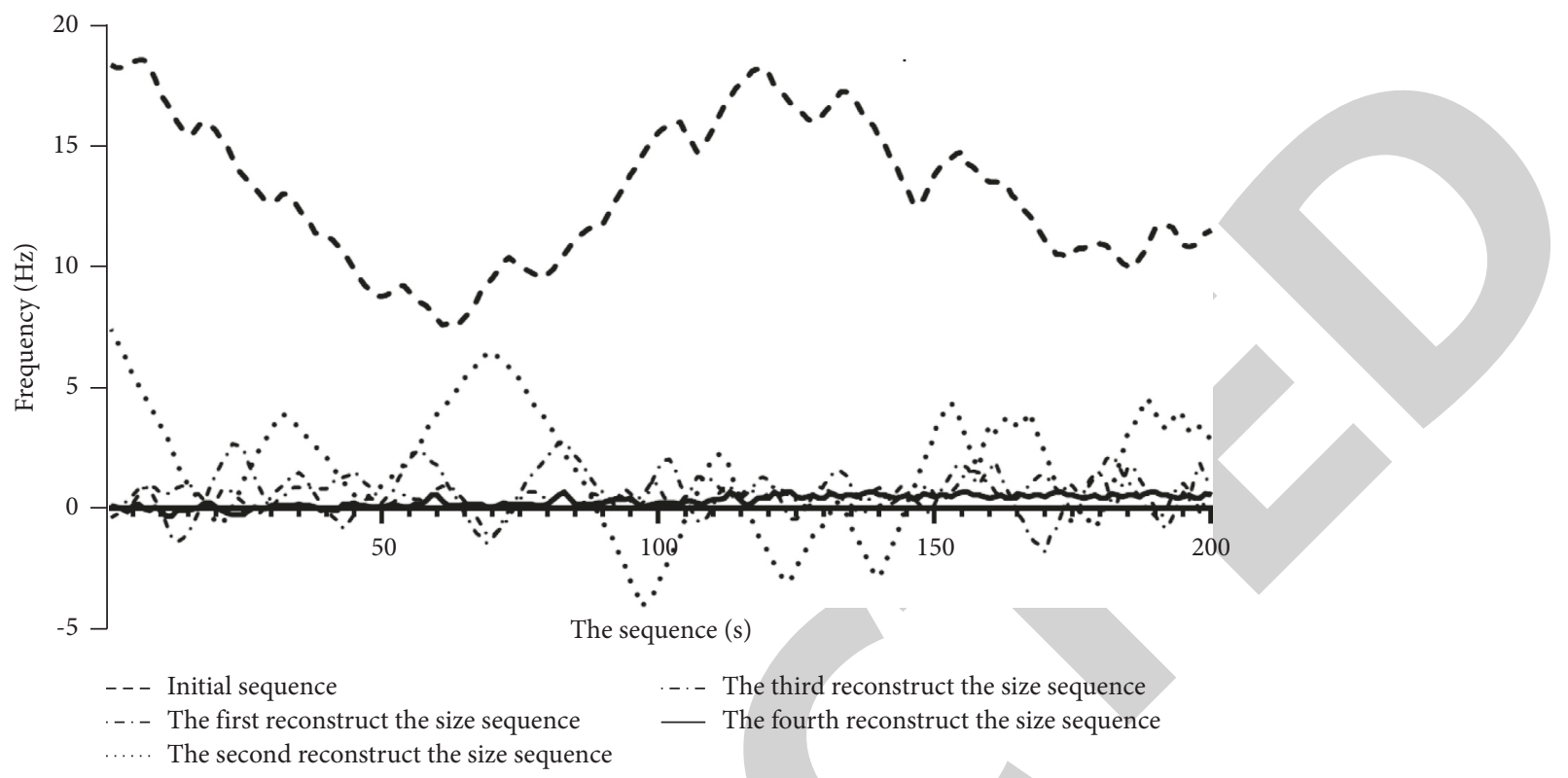

FIGURE 5: Comparison of high-frequency sequence of crude oil trade procurement model.

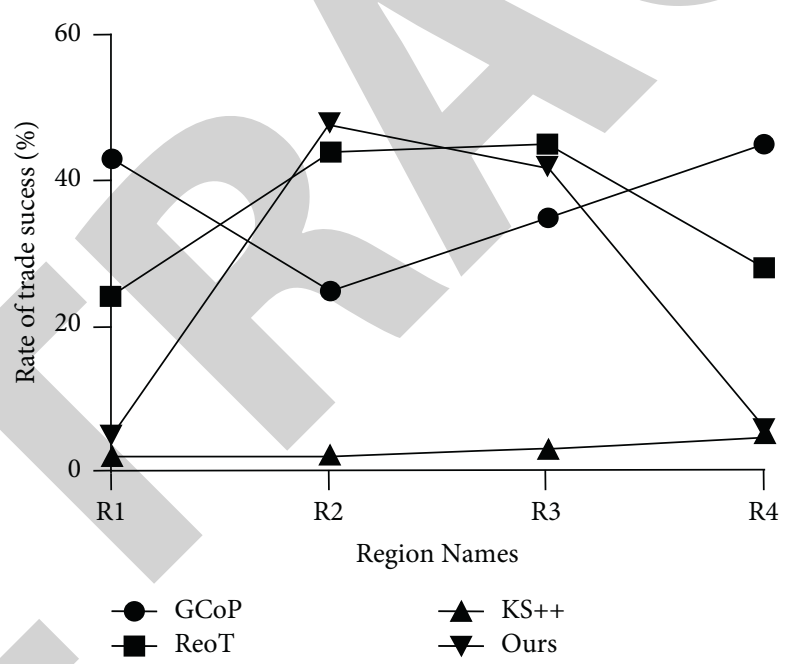

Figure 6: Rate of oil trade on different regions.

TABLE 2: The accuracy of oil trade of different neural networks on different regions.

\begin{tabular}{lcccc}
\hline & R1 & R2 & R3 & \\
\hline Proposed & $\mathbf{0 . 8 2}$ & $\mathbf{0 . 8 8}$ & $\mathbf{0 . 7 5}$ & \\
RNN & 0.66 & 0.75 & 0.62 & 0.55 \\
Bi-RNN & 0.68 & 0.73 & 0.65 & 0.41 \\
LSTM & 0.72 & 0.78 & 0.68 & 0.33 \\
Bi-LSTM & 0.80 & 0.75 & 0.70 & 0.44 \\
\hline
\end{tabular}

The demand for microbial degradable crude oil is increasing year by year. The data samples are substituted into the optimal crude oil trade procurement decision model for training. According to the training set and sample set, the experiment of mining the purchase price changes of 5 types of microbial degradable crude oil is carried out. The experimental results are shown in Figure 6. Here, five kinds of crude oil in our experiment are induced, where Type 1 represents light crude oil, Type 2 represents medium crude oil, Type 3 represents heavy crude oil, and Type 4 and Type 5 represent two types of overweight crude oil, respectively. 


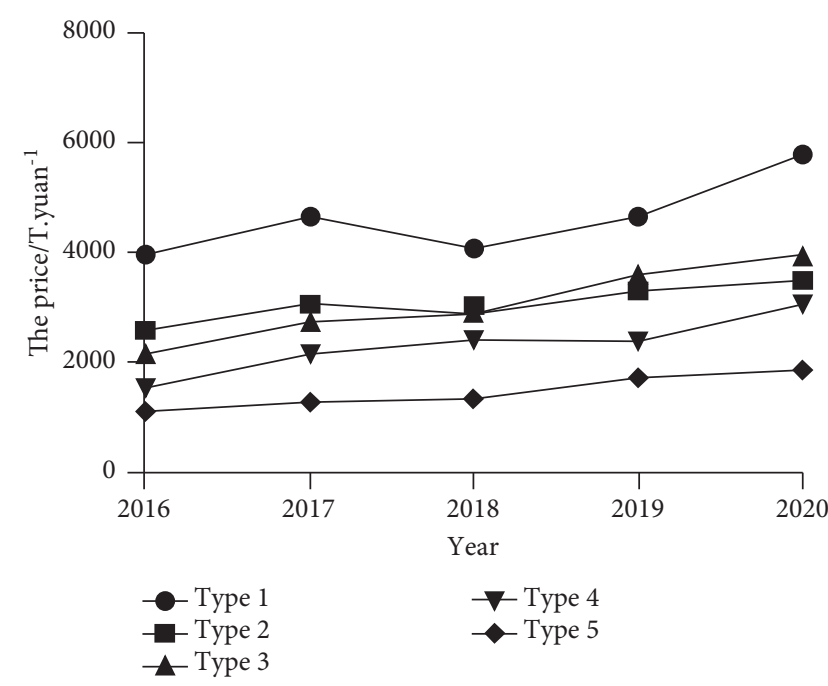

Figure 7: Diagram of price trend of microbial degradation crude oil.

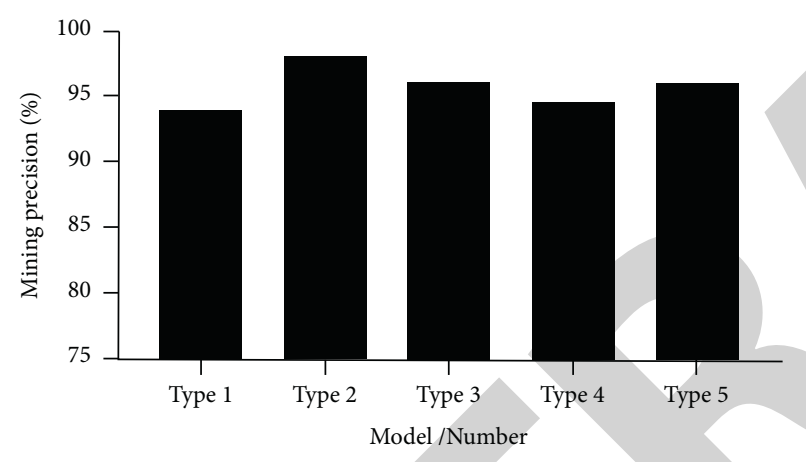

FIGURE 8: Sketch of price change mining results.

According to the price change results of the microbial degraded crude oil mined by the method in this paper over the past five years and compared with the actual statistical results, the statistical mining accuracy results are shown in Figure 7. As shown in Figure 7, the prices of all kinds of oil have increased in the recent 5 years variously, especially for Type 2 oil and Type 3 oil which are represented by two bold black lines. Type 1 oil has a small fluctuation that the piece has a slight decrease in 2018.

As can be seen from Figure 8, the mining accuracy of the price changes of all types of oils is more than 90 percent. In particular, the model obtains the highest mining accuracy of $98.62 \%$ in Type 2 oil which is more than the remaining mining accuracies of the crude oils such as $97.15 \%$ in Type 5, $96.89 \%$ in Type $3,94.27 \%$ in Type 4 , and $93.94 \%$ in Type 1. All the above results are within the acceptable error range. The results show that this method has a good mining ability and lays a solid foundation for the intelligent mining of crude oil trade procurement demand.

The proposed method has reasonable complexity as compared to state-of-the-art methods already proposed in the literature.

\section{Conclusion and Prospect}

6.1. Conclusion. The high-frequency sequence of crude oil trade procurement mode based on the DEA-Malmquist algorithm can capture the disturbance in the initial sequence, effectively reduce the number of parameters, improve convergence efficiency, and retain the sudden or hidden valuable information in the initial sequence of crude oil trade procurement mode. The crude oil trade procurement model has a good mining ability, which lays a solid foundation for intelligent mining of crude oil trade procurement needs.

6.2. Prospect. There are still many problems to be solved in the crude oil trade procurement mode, many aspects need to be improved, and the improvement of overall management capability and the continuous improvement of centralized purchase management system need to be done in a down-toearth manner. In the three aspects of the crude oil trade procurement mode, improvements need to be made:

(1) Support level: many problems in crude oil trade come from the improvement and integration of the support level, which is related to the continuous improvement of basic management personnel. At this level, we should gradually improve the purchase management system, improve management efficiency, do a good job in information integration, and gradually improve the performance level of crude oil trade procurement.

(2) Operation level: the management system of crude oil trade has been basically set up, but many factors are affecting the efficiency in operation, and the professional modules are also facing optimization requirements. From the perspective of management, the centralized purchasing department at the operational level plays a leading role and can be gradually improved in a modular and phased manner.

(3) Strategic level: active exploration is needed in this area, but the improvement of purchasing capacity depends on the improvement of overall performance of crude oil trade procurement.

From the current stage, we should actively build the support and operation capacity of crude oil trade procurement and obtain substantial improvement; on this basis, the strategic capacity of crude oil trade procurement is gradually reserved and enhanced. Although our method has achieved good prediction accuracy at present compared with other popular methods, it is still unable to achieve considerable accuracy in the face of complex environment, and the training time of the model is long, which cannot meet the purpose of real-time prediction. In the future, we will further optimize the model to improve the training speed while ensuring the accuracy. 


\section{Data Availability}

The data used to support the findings of this study are available from the corresponding author upon request.

\section{Conflicts of Interest}

The author declares that he has no conflicts of interest.

\section{References}

[1] J. Kamyk, A. Kot-Niewiadomska, and K. Galos, "The criticality of crude oil for energy security: a case of Poland," Energy, vol. 220, no. 11, Article ID 119707, 2020.

[2] M. Shahrukh, R. Srinivasan, and I. A. Karimi, "Optimal procurement of liquefied natural gas cargos from long-term contracts and spot market through mathematical programming," Industrial \& Engineering Chemistry Research, vol. 60, no. 9, pp. 147-153, 2021.

[3] E. Balli, A. Nazif Çatık, and J. B. Nugent, "Time-varying impact of oil shocks on trade balances: evidence using the TVP-VAR model," Energy, vol. 217, no. 3, Article ID 119377, 2021.

[4] Z. Song, Q. Zhu, and M. Han, "Tele-connection of global crude oil network: comparisons between direct trade and embodied flows," Energy, vol. 217, no. 10, Article ID 119359, 2021.

[5] M. Rayati, A. Sheikhi, and A. M. Ranjbar, "Optimal contract design for purchasing from frequency regulation service providers with private information," IEEE Transactions on Power Systems, vol. 34, no. 3, pp. 2445-2448, 2019.

[6] M. Alidoosti, A. Nowroozi, and A. Nickabadi, "Evaluating the web-application resiliency to business-layer DoS attacks," ETRI Journal, vol. 42, no. 3, pp. 1-13, 2020.

[7] R. Liu, J. Liu, Z. Jiang, X. Fan, and Z. Luo, “A bilevel integrated model with data-driven layer ensemble for multi-modality image fusion," IEEE Transactions on Image Processing, vol. 30, no. 12, pp. 1261-1274, 2020.

[8] S. Yang, Z. Gong, K. Ye, Y. Wei, Z. Huang, and Z. Huang, "EdgeRNN: a compact speech recognition network with spatio-temporal features for edge computing," IEEE Access, vol. 8, pp. 81468-81478, 2020.

[9] J. Zhang and D. Tao, "Empowering things with intelligence: a survey of the progress, challenges, and opportunities in artificial intelligence of things," IEEE Internet of Things Journal, vol. 8, no. 10, pp. 7789-7817, 2021.

[10] M. S. Hossain and G. Muhammad, "An audio-visual emotion recognition system using deep learning fusion for a cognitive wireless framework," IEEE Wireless Communications, vol. 26, no. 3, pp. 62-68, 2019.

[11] A El, B Gm, C Cp, D E MiaoG, and G BG, "Global environmental and nutritional assessment of national food supply patterns: Insights from a data envelopment analysis approach," Science of The Total Environment, vol. 755, no. 10, Article ID 142826, 2020.

[12] M. Nemati, R. Kazemi Matin, and M. Toloo, "A two-stage DEA model with partial impacts between inputs and outputs: application in refinery industries," Annals of Operations Research, vol. 295, no. 1, pp. 285-312, 2020.

[13] M. Tavana, K. Khalili-Damghani, F. J. Santos Arteaga, and A. Hashemi, "A Malmquist productivity index for network production systems in the energy sector," Annals of Operations Research, vol. 284, no. 1, pp. 415-445, 2020.
[14] L. Baráth, I. Fert, and T. Bojnec, "The effect of investment, LFA and Agri $\alpha$ nvironmental subsidies on the components of total factor productivity: the case of slovenian farms," Journal of Agricultural Economics, vol. 71, no. 3, pp. 853-876, 2020.

[15] L. Fan, M. Xia, P. Huang, and J. Hu, "Research on educational information platform based on cloud computing," Security and Communication Networks, vol. 2021, Article ID 3109473, 11 pages, 2021.

[16] X. Liu, Y. Lin, and S.-P. Wan, "New efficient algorithms for the centroid of an interval type-2 fuzzy set," Information Sciences, vol. 570, no. 9, pp. 468-486, 2021.

[17] L. Chen, D. Chen, and H. Wang, "Fuzzy kernel alignment with application to attribute reduction of heterogeneous data," IEEE Transactions on Fuzzy Systems, vol. 27, no. 7, pp. 1469-1478, 2019.

[18] S. Ubukata, A. Notsu, and K. Honda, "Objective functionbased rough membership C-means clustering," Information Sciences, vol. 548, no. 2, pp. 479-496, 2021.

[19] A. Mazumdar, A. Mcgregor, and S. Vorotnikova, "Storage capacity as an information-theoretic vertex cover and the index coding rate," IEEE Transactions on Information Theory, vol. 65 , no. 9 , pp. 5580-5591, 2019. 